\title{
Osteometric and Radiological Study of the Mandibular Notch
}

\author{
Estudio Osteométrico y Radiológico de la Incisura Mandibular
}

Ishwarkumar, S. ${ }^{1}$; Pillay, P. ${ }^{2}$; De Gama, B. Z. ${ }^{2}$ \& Satyapal, K. S. ${ }^{2}$

ISHWARKUMAR, S.; PILlAY, P.; DE GAMA, B. Z. \& SATYAPAL, K. S. Osteometric and radiological study of the mandibular notch. Int. J. Morphol., 37(2):491-497, 2019.

SUMMARY: The mandibular notch is located on the superior margin, between two prominent processes of the mandibular ramus, the coronoid and condylar processes. The mandibular notch permits the entry of the masseteric artery, vein and nerve to the deep surface the masseteric muscle. Literary reports documented variations in both, the shape and size of the mandibular notch. Therefore, this study aimed to document the morphology and morphometry of the mandibular notch in the South African Black and Indian population groups and to determine their relationship to sex, age and race (if any). The morphometric and morphological parameters of the mandibular notch were measured and assessed in 149 digital panoramic radiographs and 51 dry mandible specimens ( $\mathrm{n}=400)$ belonging to the South African Black African and Indian population groups. A combination of classification schemes by Mohammad et al. (2012) and Shakya et al. (2013) were adopted to assess the morphology of the mandibular notch. The morphometric parameter was measured using the Dicom X-ray viewer and a digital vernier caliper. Each of the morphometric and morphological parameters were statistically analyzed using SPSS, to determine if a relationship existed between the afore-mentioned parameters and sex, age and race. This study recorded the round shaped mandibular notch to be the most prevalent type in both sexes with a combined incidence of $44.2 \%$. The length of the mandibular notch was reported to be greater in males than females and concurred with previous studies. However, the selected South African group displayed a smaller mandibular notch than the Japanese and Chinese population groups. Furthermore, this study documented population differences among the South African population group, as the Black African population group showed a wider mandibular notch than the Indian population group. This suggests that population-specific differences may exist for both the morphological and morphometric parameters of the mandibular notch. However, only a statistically significant relationship between the length of the mandibular notch with age and race was documented. The mandibular notch may be of clinical significance to maxillofacial surgeons for surgical and reconstructive procedures, in addition it may also aid forensic anthropologists in the identification of unknown remains.

KEY WORDS: Mandibular notch; Mandibles; Panoramic radiographs; Osteology; Morphology.

\section{INTRODUCTION}

The mandibular notch, also referred to as the incisura mandibulae or sigmoid notch, is a gap facing upwards and backwards occupying the superior margin of the mandibular ramus (Stedman, 2012; Mohammad et al. 2012; Mosby Inc., 2013). Furthermore, this notch separates two prominent processes of the mandibular ramus, viz. the coronoid process (superiorly) and the condylar process (anteriorly) (Standring, 2008). The mandibular notch acts as a passageway for the masseteric artery (accompanied by the masseteric vein and nerve) to enter the deep surface the masseteric muscle (Standring; Mohammad et al.).

Morphometric and morphological studies regarding the mandibular notch have been reviewed; however there is a paucity of literature regarding data in the South African population. The morphometry of the male mandibular notch was greater than that of females and the length of the notch differed among population groups, viz. Japanese and Chinese (Suzuki \& Takahashi, 1975; Huang, 2003). In addition, the shapes of the mandibular notch were variable in literary reports, viz: round, sloping, wide, triangular and quadrilateral shapes (Mohammad et al.; Shakya et al.; Sahithi et al., 2016). In addition to populationspecific differences, intra-population differences were also noted, as the sloping shape was most prevalent in the South Indian population group, while in the North Indian population, the wide shape mandibular notch was most prevalent (Shakya et al.; Sahithi et al.). Therefore,

\footnotetext{
${ }^{1}$ Department of Human Anatomy and Physiology Faculty of Health Sciences University of Johannesburg Doornfontein Campus P.O Box 524 Auckland Park, South Africa.

${ }^{2}$ Department of Clinical Anatomy School of Laboratory Medicine and Medical Sciences College of Health Sciences University of KwaZulu-Natal Westville Campus Private Bag X54001, Durban.
} 
population-specific differences exist with regard to the length and shape of the mandibular notch.

The mandibular notch is clinically significant for surgical and reconstructive procedures, as it assists maxillofacial surgeons in their surgical approach and management within this region (Clauser et al., 1995; Mintz et al., 1998; Mohammad et al.). Therefore, this study documents the morphology and morphometry of the mandibular notch in order to determine their relationship to sex, age and race (if any).

\section{MATERIAL AND METHOD}

General. This study examined 149 digital panoramic radiographs and 51 dry mandible specimens bilaterally $(\mathrm{n}=400)$. There were 97 South African Black and 103 Indian (103), 94 male and 106 female radiographs. The digital panoramic radiographs were obtained from private practices within the eThekwini municipality metropolitan region, while the dry mandible specimens were obtained from the osteological bank of Clinical Anatomy, School of Laboratory Medicine and Medical Sciences at the Nelson R Mandela School of Medicine at the University of KwaZulu-Natal. Both the digital panoramic radiographs and dry mandible specimens were obtained utilizing consecutive sampling. The age, sex and race of the radiographs and specimens in question were obtained from the patient and departmental records, respectively. Ethical clearance was obtained BE 410/13. Panoramic radiographs of patients who presented with no history of trauma or pathological changes and had complete patient records were included in this study, while mandibles that were eroded, broken and deformed were excluded.

Methodology. The panoramic radiographs and dry mandible specimens were examined by the principle investigator, using a Dicom x-ray viewer and a digital vernier caliper, respectively. The dry bone results were photographed using a Samsung digital camera (C650) and both sets of data were captured on Microsoft excel data sheet.

Morphological parameters. In this study, the morphology of the notch was based on a combination of two classification schemes, viz. Mohammad et al. and Shakya et al. (Table I).

Morphometric parameter. The length of the mandibular notch was measured from the anterior surface of the head of the mandible to the posterior surface of the coronoid process (Fig. 1. A-B).
Table I. The morphology of the mandibular notch in osteological and radiological specimens
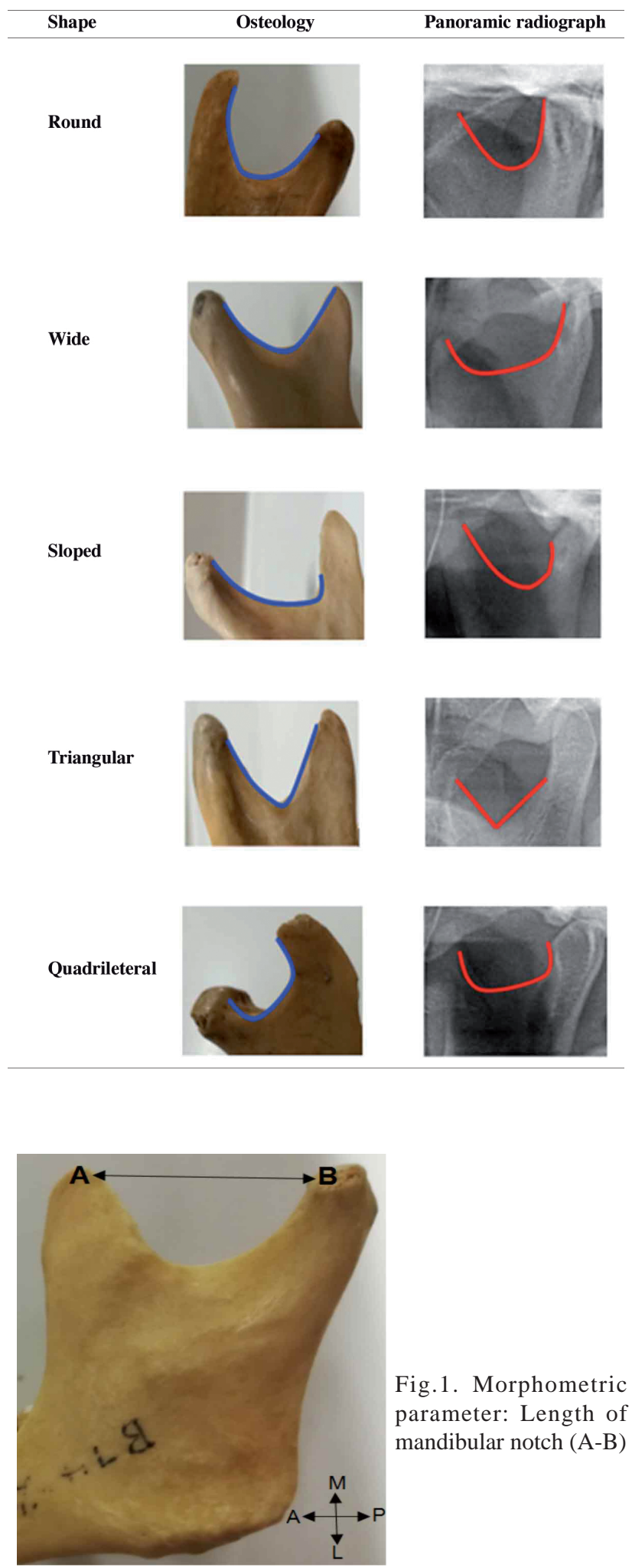
Statistical Analysis. The collected data was captured and analysed using the Statistical Package for Social Sciences (SPSS version 23.0). The Pearson Chi-Square test and Independent Sample T-test was used to analyse the relationship between age, sex, race, and the shape and length of the mandibular notch. A $95 \%$ confidence level was adhered to for all statistical tests. A p-value of less than 0.05 was considered to be statistically significant.
Intra-observer reliability. The principle investigator assessed the morphological and morphometric parameters of the mandibular notch on two separate occasions to ensure reliability and validity. The Intraclass Correlation Coefficient Test was then utilized to compare the two sets of data.

\section{RESULTS}

Table II. The morphology and morphometry of the mandibular notch with regard to sex (in \%).

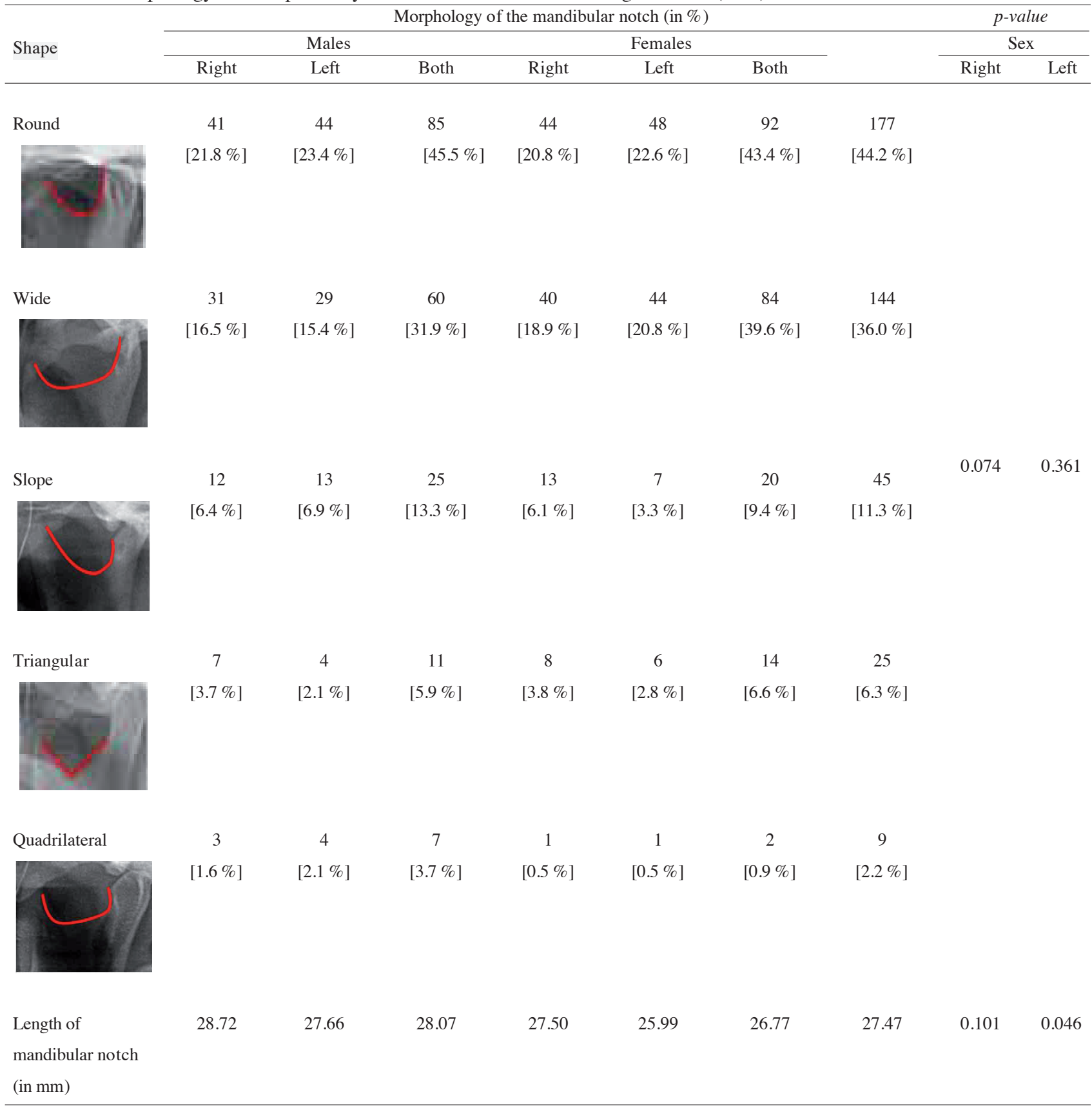


Morphology of the mandibular notch. The round shape was most prevalent in $44.2 \%$ of the sample, this was followed by the wide $(36.0 \%)$, sloped $(11.3 \%)$, triangu$\operatorname{lar}(6.3 \%)$ and quadrilateral (2.2\%) shapes, respectively (Table II). With regard to sex, the round shape mandibular notch was most prevalent in $45.2 \%$ and $43.4 \%$ in males and females, respectively (Table II). The quadrilateral shaped mandibular notch was least prevalent in both, males $(3.7 \%)$ and females $(0.9 \%)$ (Table II). There was no statistically significant difference reported between sex and the shape of the mandibular notch (Table II). The shape of the mandibular notch did not vary significantly overtime, as round shaped mandibular notch was most prevalent in $44.8 \%$ and $43.3 \%$ in the $13-29$ and 30-80 year age cohorts, respectively (Table III). There was no statistically significant difference between age and the shape of the mandibular notch (Table III).

Length of the mandibular notch. The length of the mandibular notch was greater in males than females, with a length of $28.07 \mathrm{~mm}$ and $26.77 \mathrm{~mm}$, respectively (Table II). The length of the mandibular notch in male was recorded to be $28.72 \mathrm{~mm}$ and $27.66 \mathrm{~mm}$ on the right and left side, respectively, while in females it was noted to be smaller, with a length of $27.50 \mathrm{~mm}$ and $25.99 \mathrm{~mm}$ on the right and left side, respectively (Table II). There was no statistically significant difference between the length of the mandibular notch and sex (Table II). The length of the mandibular notch was $25.57 \mathrm{~mm}$ in the 13-29 year age cohort and $30.51 \mathrm{~mm}$ in the $30-80$ year age cohort (Table III). The length of the mandibular notch recorded statistically significant relationship with age ( $p-$ value $=0.000)$ (Table III).

Racial difference regarding the mandibular notch. This study documented the shape and size of the mandibular notch in the Black African and Indian South African population groups within the KwaZulu-Natal province. With regard to the morphology of the mandibular notch, the round shape $(51.0 \%)$ was most prevalent in the Indian population, while

Table III. Morphology and morphometry of the mandibular notch in two age cohorts.

\begin{tabular}{|c|c|c|c|c|c|c|c|c|}
\hline \multirow{3}{*}{ Shape } & \multicolumn{6}{|c|}{ Morphology of the mandibular notch (in \%) } & \multirow{2}{*}{\multicolumn{2}{|c|}{$\begin{array}{c}p \text {-value } \\
\text { Age }\end{array}$}} \\
\hline & \multicolumn{3}{|c|}{$13-29(n=250)$} & \multicolumn{3}{|c|}{$30-80(\mathrm{n}=150)$} & & \\
\hline & Right & Left & Both & Right & Left & Both & Right & Left \\
\hline \multirow[t]{2}{*}{ Round } & 53 & 59 & 112 & 32 & 33 & 65 & & \\
\hline & [21.2\%] & [23.6\%] & [44.8\%] & [21.3\%] & {$[22.0 \%]$} & [43.3\%] & & \\
\hline \multirow[t]{2}{*}{ Wide } & 46 & 43 & 89 & 25 & 30 & 55 & & \\
\hline & [18.4\%] & {$[17.2 \%]$} & {$[35.6 \%]$} & [16.7\%] & {$[20.0 \%]$} & [36.7\%] & & \\
\hline \multirow[t]{2}{*}{ Slope } & 13 & 14 & 27 & 12 & 6 & 18 & 0.646 & 0.494 \\
\hline & [5.2\%] & [5.6\%] & [10.8\%] & {$[8.0 \%]$} & {$[4.0 \%]$} & [12.0\%] & & \\
\hline \multirow[t]{2}{*}{ Triangular } & 7 & 4 & 15 & 5 & 5 & 10 & & \\
\hline & {$[4.0 \%]$} & [2.0\%] & {$[6.0 \%]$} & {$[3.3 \%]$} & [3.3\%] & {$[6.6 \%]$} & & \\
\hline \multirow[t]{2}{*}{ Quadrilateral } & 3 & 4 & 7 & 1 & 1 & 2 & & \\
\hline & {$[1.2 \%]$} & [1.6\%] & [2.8\%] & {$[0.7 \%]$} & {$[0.7 \%]$} & {$[1.3 \%]$} & & \\
\hline $\begin{array}{l}\text { Length of mandibular } \\
\text { notch (in mm) }\end{array}$ & 26.51 & 24.63 & 25.57 & 30.68 & 30.34 & 30.51 & 0.000 & 0.000 \\
\hline
\end{tabular}

Table IV. The morphology and morphometry of the mandibular notch in two ethnic groups (in \%).

\begin{tabular}{|c|c|c|c|c|c|c|c|c|c|}
\hline \multirow[t]{3}{*}{ Shape } & \multicolumn{7}{|c|}{ Morphology of the mandibular notch (in \%) } & \multirow{2}{*}{\multicolumn{2}{|c|}{$\begin{array}{c}p \text {-value } \\
\text { Race }\end{array}$}} \\
\hline & & $\operatorname{dian}(\mathrm{n}=2 \mathrm{C}$ & & & lack $(n=1$ & & & & \\
\hline & Right & Left & Both & Right & Left & Both & Both & Right & Left \\
\hline Round & $\begin{array}{c}50 \\
{[24.3 \%]}\end{array}$ & $\begin{array}{c}55 \\
{[26.7 \%]}\end{array}$ & $\begin{array}{l}105 \\
{[51.0 \%]}\end{array}$ & $\begin{array}{c}35 \\
{[18.0 \%]}\end{array}$ & $\begin{array}{c}37 \\
{[19.1 \%]}\end{array}$ & $\begin{array}{c}72 \\
{[37.1 \%]}\end{array}$ & $\begin{array}{c}177 \\
{[44.2 \%]}\end{array}$ & & \\
\hline Wide & $\begin{array}{c}35 \\
{[17.0 \%]}\end{array}$ & $\begin{array}{c}31 \\
{[15.0 \%]}\end{array}$ & $\begin{array}{c}66 \\
{[32.0 \%]}\end{array}$ & $\begin{array}{c}36 \\
{[18.6 \%]}\end{array}$ & $\begin{array}{c}42 \\
{[21.6 \%]}\end{array}$ & $\begin{array}{c}78 \\
{[40.2 \%]}\end{array}$ & $\begin{array}{c}144 \\
{[39.0 \%]}\end{array}$ & 0.135 & 0.196 \\
\hline Slope & $\begin{array}{c}8 \\
{[3.9 \%]}\end{array}$ & $\begin{array}{c}10 \\
{[4.7 \%]}\end{array}$ & $\begin{array}{c}18 \\
{[8.7 \%]}\end{array}$ & $\begin{array}{c}17 \\
{[8.8 \%]}\end{array}$ & $\begin{array}{c}10 \\
{[5.2 \%]}\end{array}$ & $\begin{array}{c}27 \\
{[13.9 \%]}\end{array}$ & $\begin{array}{c}45 \\
{[11.3 \%]}\end{array}$ & & \\
\hline Triangular & $\begin{array}{c}8 \\
{[3.9 \%]}\end{array}$ & $\begin{array}{c}4 \\
{[1.9 \%]}\end{array}$ & $\begin{array}{c}12 \\
{[5.8 \%]}\end{array}$ & $\begin{array}{c}7 \\
{[3.6 \%]}\end{array}$ & $\begin{array}{c}6 \\
{[3.1 \%]}\end{array}$ & $\begin{array}{c}13 \\
{[6.7 \%]}\end{array}$ & $\begin{array}{c}25 \\
{[6.3 \%]}\end{array}$ & & \\
\hline Quadrilateral & $\begin{array}{c}2 \\
{[1.0 \%]}\end{array}$ & $\begin{array}{c}3 \\
{[1.5 \%]}\end{array}$ & $\begin{array}{c}5 \\
{[2.4 \%]}\end{array}$ & $\begin{array}{c}2 \\
{[1.0 \%]}\end{array}$ & $\begin{array}{c}2 \\
{[1.0 \%]}\end{array}$ & $\begin{array}{c}4 \\
{[2.0 \%]}\end{array}$ & $\begin{array}{c}9 \\
{[2.2 \%]}\end{array}$ & & \\
\hline $\begin{array}{l}\text { Length of } \\
\text { mandibular notch } \\
\text { (in mm) }\end{array}$ & 26.74 & 24.95 & 25.85 & 29.48 & 28.72 & 29.10 & 27.48 & 0.000 & 0.000 \\
\hline
\end{tabular}


the wide shape $(40.2 \%)$ was most common in the Black African population (Table IV). The quadrilateral shape was least prevalent in both population groups, with an incidence of $2.4 \%$ and $2.1 \%$ in the Indian and Black African population groups, respectively (Table IV). With regard to the morphometry, the length of the mandibular notch was greater in the Black African population group than the Indian population group, with a mean length of $29.10 \mathrm{~mm}$ and 25.85 mm, respectively (Table IV). Furthermore, a statistically significant relationship between the length of the mandibular notch and race was recorded in this study (Table IV).

Reliability and validity. The first author assessed all digital panoramic radiographs twice, yielding an Intra-Class Correlation Coefficient of 0.806, which donates excellent agreement $(\max =1)($ Cicchetti et al., 1994).

\section{DISCUSSION}

Morphology of the mandibular notch. In the present study, the most prevalent shape of the mandibular notch was the round shape, with an incidence of $44.2 \%$. This was followed by the wide $(36.0 \%)$, sloped $(11.3 \%)$ and triangular $(6.3 \%)$ shapes, respectively, with the least prevalent shape being quadrilateral shape in $2.2 \%$ of the sample (Table V). However, these results differed from previous studies, as Mohammed et al. (2012) reported that the triangular shape was the most prevalent in the Iraqi population, while Shakya et al. and Sahithi et al. found that the sloped $(45.5 \%)$ and wide $(43.5 \%)$ shapes were most common in the North and South Indian population groups, respectively (Table V). With regard to age, the present study documented that the round shaped mandibular notch was most prevalent in both the 13-29 year and 30-80 year age cohorts, with an incidence of 44.8 $\%$ and $43.3 \%$, respectively. However, Shakya et al. reported that the wide shaped $(44.2 \%)$ mandibular notch was most prevalent in individuals older than 30 years in South India. The latter supports the view that populationspecific differences may also exist. However, this study found no statistically significant difference between the shape of the mandibular notch with age, sex and race ( $p$ value $>0.05$ ). Similarly, previous studies reported no statistically difference between the shape of the mandibular notch and sex (Shakya et al.; Sahithi et al.).

Length of the mandibular notch. In the current study, the length of the mandibular notch was recorded to be greater in males than females, with a mean length of $28.07 \mathrm{~mm}$ in male and $26.77 \mathrm{~mm}$ in females (Table VI). These findings correlated with previous studies conducted by Suzuki \& Takahashi and Huang, who also reported a longer mandibular notch in males than females (Table VI). Despite this similarity, it should be noted that variations regarding the length of the mandibular notch between the population groups exist, as the selected South African population groups reported a smaller mandibular notch than the Japanese and Chinese population groups (Suzuki \& Takahashi; Huang) (Table VI). Therefore, it may be postulated that population-specific differences regarding the morphometry of the mandibular notch exist. Furthermore, in this study the length of the mandibular notch recorded a statistically significant relationship with age only (p-value=0.000). Haung et al. (2003) reported that there was no statistical difference between males and females with regard to the length of the mandibular notch, which correlated with this study (Table II).

Racial difference regarding the mandibular notch. This study documented population-specific differences with regard to the shape and size of the mandibular notch among the South African Black African and Indian population groups. Similarly, Shakya et al. and Sahithi et al., as intra population-specific differences were highlighted between the North and South Indian population groups of India. In the present study, the most prevalent shaped mandibular notch was round and wide shapes in the Indian and Black African population groups, respectively. Whereas, in the South and North Indian population groups it was reported that the sloped and wide shapes were most prevalent, with an incidence of $45.5 \%$ and $43.5 \%$, respectively (Shakya et al.; Sahithi et al.). With regard to morphometry in the present study, the Black African population group displayed a longer mandibular notch than the Indian population group, with a mean length of $29.10 \mathrm{~mm}$ and $25.85 \mathrm{~mm}$, respectively. A statistically significant relationship between the length of the mandibular notch and race was recorded in this study.

Table V. A comparison of the prevalence regarding shape of the mandibular notch (in \%).

\begin{tabular}{|c|c|c|c|c|c|c|c|}
\hline \multirow[t]{2}{*}{ Author } & \multirow[t]{2}{*}{ Population } & \multirow[t]{2}{*}{ Sample $\mathrm{n}$} & \multicolumn{5}{|c|}{ Shape of the mandibular notch (\%) } \\
\hline & & & Round & Slope & Wide & Triangular & Quadrilateral \\
\hline Mohammad et al. (2012) & Iraqi & 100 & 34.0 & - & - & 46.0 & 20.0 \\
\hline Shakya et al. (2013) & South Indian & 200 & 30.8 & 45.5 & 23.8 & - & - \\
\hline Sahithi et al. (2016) & North Indian & 200 & 33.3 & 23.3 & 43.5 & - & - \\
\hline Present Study & South Africa & 200 & 44.2 & 36.0 & 11.3 & 6.3 & 2.2 \\
\hline
\end{tabular}


Table VI. The length of the mandibular notch (in $\mathrm{mm}$ ).

\begin{tabular}{lcccc}
\hline \multicolumn{1}{c}{ Author } & Population & Sample $\mathrm{n}$ & \multicolumn{2}{c}{$\begin{array}{c}\text { Length of the mandibular notch (mm) } \\
\text { Male }\end{array}$} \\
\hline Suzuki \& Takahashi (1975) & Japanese & 112 & 34.22 & 33.68 \\
Haung (2003) & Chinese & 153 & 34.20 & 32.69 \\
Present Study & South Africa & 200 & 28.07 & 26.77 \\
\hline
\end{tabular}

\section{CONCLUSION}

This study demonstrated that the round shape mandibular notch was the most prevalent in both sexes. The length of the mandibular notch was reported to be greater in males than females and this concurred with previous studies (Suzuki \& Takahashi; Haung, 2003). However, the length of the mandibular notch in the selected South African population group was smaller than the Japanese and Chinese population. Furthermore, this study elucidated population differences among the Black African and Indian population groups of South Africa, as the Black African population group displayed a wider and longer mandibular notch than the Indian population group, thereby indicating that population-specific differences may exist for both the morphological and morphometric parameters of the mandibular notch. However, only a statistically significant relationship between the length of the mandibular notch with age and race was documented. Knowledge of the anatomy of the mandibular notch may assist maxillofacial surgeons during reconstructive and surgical procedures, as it may aid in the surgical approach and management within this region. In addition, it may also aid forensic anthropologists in the identification of unknown remains.

ISHWARKUMAR, S.; PILLAY, P.; DE GAMA, B. Z. \& SATYAPAL, K. S. Estudio osteométrico y radiológico de la incisura mandibular. Int. J. Morphol., 37(2):491-497, 2019.

RESUMEN: La incisura mandibular se encuentra en el margen superior, entre dos procesos importantes de la rama mandibular, el proceso coronoides y el proceso condilar. La incisura mandibular permite la entrada de la arteria, la vena y el nervio masetérico en la superficie profunda del músculo masetero. En la literatura se han documentado variaciones tanto en la forma como en el tamaño de la incisura mandibular. Este estudio tuvo como objetivo documentar la morfología y la morfometría de la incisura mandibular en los grupos de población de negros e indios sudafricanos y determinar su relación con el sexo, la edad y la raza. Los parámetros morfométricos y morfológicos de la incisura mandibular se midieron y evaluaron en 149 radiografías panorámicas digitales y 51 especímenes de mandíbula seca $(n=400)$ pertenecientes a los grupos de población sudafricana negra e india. Una combinación de esquemas de clasificación de Mohammad et al. (2012) y Shakya et al. (2013) fueron adoptados para evaluar la morfología de la incisura mandibular. El parámetro morfométrico se midió utilizando el visor de rayos X Dicom y un calibrador Vernier digital. Cada uno de los parámetros morfométricos y morfológicos se analizaron estadísticamente utilizando el software SPSS, para determinar si existía una relación entre los parámetros mencionados anteriormente y el sexo, la edad y la raza. Este estudio registró la incisura mandibular de forma redonda como el tipo más prevalente en ambos sexos, con una incidencia de un 44,2\%. Se informó que la longitud de la incisura mandibular es mayor en hombres que en mujeres y coincidió con estudios anteriores. Sin embargo, el grupo sudafricano seleccionado mostró una incisura mandibular más pequeña que los grupos de población japoneses y chinos. Además, se documentó las diferencias de población entre el grupo de Sudáfrica, ya que el grupo de población negra de África mostró una incisura mandibular más amplia que el grupo de la población India. Esto sugiere que pueden existir diferencias específicas de la población para los parámetros morfológicos y morfométricos de la incisura mandibular. Sin embargo, solo se documentó una relación estadísticamente significativa entre la longitud de la incisura mandibular con la edad y la raza. La incisura mandibular puede ser de importancia clínica para los cirujanos maxilofaciales en procedimientos quirúrgicos y reconstructivos; además, también puede ayudar a los antropólogos forenses en la identificación de restos desconocidos.

PALABRAS CLAVE: Incisura mandibular; Mandíbula; Radiografía panorámica; Osteología; Morfología.

\section{REFERENCES}

Clauser, L.; Curioni, C. \& Spanio, S. The use of the temporalis muscle flap in facial and craniofacial reconstructive surgery. A review of 182 cases. J. Craniomaxillofac. Surg., 23(4):203-14, 1995.

Huang, J. Study on the location of mandibular foramen and the measurement of sigmoid notch and ramus. Shanghai Kou Qiang Yi Xue, 12(4):2847, 2003.

Mintz, S. M.; Ettinger, A.; Schmakel, T. \& Gleason, M. J. Contralateral coronoid process bone grafts for orbital floor reconstruction: an anatomic and clinical study. J. Oral Maxillofac. Surg., 56(10):1140-4, 1998.

Mohammad, S. A.; Mohammad, A. \& Mahdi, A. J. J. Mandibular notch configuration in Iraqi adults. Tikrit J. Dent. Sci., 2:175-8, 2012.

Mosby Inc. Mosby's Dictionary of Medicine, Nursing \& Health Professions. $9^{\text {th }}$ ed. St. Louis, Elsevier/Mosby, 2013.

Sahithi, D.; Reddy, S.; Teja, D. D. V.; Koneru, J.; Praveen, K. N. S. \& Sruthi, R. Reveal the concealed - Morphological variations of the 
coronoid process, condyle and sigmoid notch in personal identification. Egypt. J. Forensic Sci., 6(2):108-13, 2016.

Shakya S, Ongole R, Nagraj SK. Morphology of coronoid process and sigmoid notch in orthopantomograms of South Indian population. World J. Dent., 4(1):1-3, 2013.

Standring, S. Gray's Anatomy. The Anatomical Basis of Clinical Practice. $40^{\text {th }}$ ed. Edinburgh, Churchill Livingstone/Elsevier, 2008. pp.499-524.

Stedman, T. L. Stedman's Medical Dictionary for the Health Professions and Nursing. Philadelphia, Wolters Kluwer Health/Lippincott Williams \& Wilkins, 2012.

Suzuki, M. \& Takahashi, Y. Anthropological studies on the mandible of the recent Chubu Japanese. J. Anthropol. Soc. Nippon, 83(4):320-9, 1975.
Corresponding author:

Professor K.S. Satyapal

Department of Clinical Anatomy

School of Laboratory Medicine and Medical Sciences

College of Health Sciences

University of KwaZulu-Natal

Private Bag X54001

Durban 4000

SOUTH AFRICA

Email: satyapalk@ukzn.ac.za

Received: 26-09-2018

Accepted: $21-01-2019$ 